\title{
Procesos de educación intercultural y autosegregación indígena en los aimaras de Puno, Perú
}

\author{
Processes of intercultural education and indigenous self-segregation in the \\ Aimaras of Puno, Perú
}

Processos de educação intercultural e auto-segregação indígena nos aimarás de Puno, Perú

Recepción: 15/11/2019

Evaluación: 01/03/2020

Aceptación: 01/04/2020

Artículo de Investigación - Revisión

https://doi.org/10.19053/01227238.10101

https://orcid.org/0000-0001-9885-7974
Yanet Amanda Maquera Maquera ${ }^{2}$
https://orcid.org/0000-0002-2492-6428

Luz Yohana Bermejo Gonzáles ${ }^{3}$

https://orcid.org/0000-0003-4910-759X

Universidad Nacional del Altiplano de Puno, Perú

\section{RESUMEN}

El objetivo del estudio es interpretar desde la racionalidad aimara, cómo los procesos de educación intercultural bilingüe (EIB) desarrollados en las escuelas rurales de la zona aimara de Puno-Perú, generan como resultado después de cuarenta años, el fenómeno de la autosegregación indígena. Originalidad: la autosegregación no se encuentra explicitada como meta $\mathrm{u}$ objetivo por ninguna política o programa EIB; es una temática nueva y vinculante para redefinir, la educación impartida en las poblaciones indígenas. Método: es un trabajo de investigación cualitativa-hermenéutica que, empleando las estrategias del análisis documental y las entrevistas en profundidad; interpreta los resultados, mediante el proceso de análisis de contenido, fundamentalmente, permitiendo establecer como conclusión que, la EIB desde la racionalidad aimara cobra

$1 \quad$ Docente principal de la Universidad Nacional del Altiplano de Puno (Perú), doctor en Educación, calificado como investigador RENACYT por el Consejo Nacional de Ciencia, Tecnología e Innovación (CONCYTEC-Perú), correo electrónico: saulbermejo@ gmail.com.

2 Doctora en Educación, docente de la Universidad Nacional del Altiplano de Puno (Perú), correo electrónico: yanelaamanda76@ gmail.com

3 Doctora en Ciencias de la Salud, Universidad Nacional del Altiplano de Puno (Perú), correo electrónico: luyoha8@gmail.com . 
solamente un valor simbólico, se percibe como un programa racista, que a través del tiempo ha provocado, un paulatino desplazamiento lingüístico del aimara por el castellano y la folclorización de la sabiduría y la cultura aimara; situación que simultáneamente, ha posibilitado la emergencia de la autosegregación indígena, como estrategia y racionalidad para redefinir la EIB, la educación en general y la subsistencia de la nación aimara.

Palabras clave: Aimara; autosegregación indígena; diversidad lingüística; educación intercultural; identidad cultural.
The objective of the study is to interpret from the Aymara thinking, how the processes of bilingual intercultural education (IBE) developed in rural schools in the Aymara area of Puno-Peru, generate the phenomenon of indigenous self-segregation after forty years. Self-segregation is not specified as a goal or objective by any EIB policy or program; It is conceived as a driving force for the construction of strategic alliances to conduct its own educational purposes, keeping the Aymara culture and language alive, without disassociating itself from national and world society. This has to do with a new and binding theme to redefine such as the education provided in indigenous populations. It is a qualitative-hermeneutic research work that, using the techniques of documentary analysis and in-depth interviews; the results are studied, through the content analysis process, fundamentally; allowing to establish as a conclusion that from the Aymara thinking the EIB only receives a symbolic value, it is perceived as a racist program which over time has caused a gradual linguistic displacement of the Aymara by the Spanish and the folklore of wisdom and Aymara culture; situation that simultaneously has made possible the emergence of indigenous self-segregation, as a strategy and rationale to redefine IBE, education in general and the livelihood of the Aymara nation.

Keywords: Aimara; indigenous self-segregation; linguistic diversity; intercultural education; cultural identity.

\section{RESUMO}

O objetivo do estudo é interpretar, a partir da racionalidade aimará, como os processos de educação intercultural bilíngue (EIB) desenvolvidos em escolas rurais da região de aymara, em Puno-Perú, geram como resultado, após quarenta anos, o fenômeno da auto-segregação indígena. A auto-segregação não é especificada como meta ou objetivo em nenhuma política ou programa do EIB; É gestado como um movimento que promove a construção de alianças estratégicas para delinear seus próprios propósitos educacionais, mantendo viva a cultura e a língua aimara, sem se desas sociar da sociedade nacional e mundial; Constituindo, assim, um tema novo e vinculativo para redefinir a educação oferecida às populações indígenas. Trata-se de um trabalho de pesquisa qualitativo-hermenêutica que, utilizando as técnicas de análise documental e entrevistas em profundidade; interpreta os resultados, através do processo de análise de conteúdo, fundamentalmente; permitindo concluir que, o EIB da racionalidade aimara recebe apenas um valor simbólico, é percebido como um programa racista que, com o tempo, causou um deslocamento linguístico gradual do aimara pelo castelhano e pelo folclore da sabedoria e da cultura aimara; situação que simultaneamente possibilitou o surgimento da auto-segregação indígena, como 
estratégia e lógica para redefinir a EIB, a educação em geral e os meios de subsistência da nação aimara.
Palabras clave: Aymara; auto-coleta indígena; diversidade lingüística; educação intercultural; identidade cultural.

\section{INTRODUCCIÓN}

La interculturalidad nace con propósitos distintos y en contextos distintos; según Abdallah-Pretceille, aparece en Francia en 1975, relacionada con la inmigración en el marco de proyectos sociales y educativos y como respuesta a las profundas raíces ideológicas del tradicional republicanismo francés; por su parte, Borboa-Trasviña ${ }^{5}$ refiere que fue en Alemania, en 1979, ligada a programas compensatorios, convirtiéndose en la clave de un enfoque educativo que considera el respeto por los derechos humanos, la diversidad cultural, la fuerza y valor de la multiculturalidad, el refuerzo de la identidad cultural, el proceso recíproco de aprendizaje entre las culturas, el diálogo cultural basado en la relación interactiva y la igualdad de oportunidades para todas las personas. En 1940, se llevó a cabo en Pátzcuaro (Estado de Michoacán, México) el Primer Congreso Indigenista Interamericano, que introduce la educación bilingüe como una modalidad compensatoria; en América Latina y específicamente en el Perú, el concepto de EIB ingresa a inicios de 1980, como una propuesta enraizada en la cultura de los educandos e impartida en español y lengua indígena ${ }^{6}$.

Hace más de cuarenta años se apela a la interculturalidad en la educación que, considerada como noción y como mecanismo, es capaz de dotar de mayor calidad y equidad a las propuestas educativas. En ese contexto, en el Perú ha sido la región de Puno la pionera en incorporar a la educación la perspectiva intercultural y es ya larga su práctica de implementar programas de educación bilingüe $^{7}$ con relación a otras zonas del país e incluso de Latinoamérica. Y no es mera casualidad o coincidencia que la educación bilingüe empezara aquí. Puno ha sido históricamente la región que, con mayor concentración de población indígena quechua y aimara, ha soportado la servidumbre y la explotación impuestas por el poder colonial y republicano. Por tanto, se vio a la escuela como un mecanismo para dejar atrás la servidumbre y la marginación' ${ }^{9}$, avanzar

$4 \quad$ Martine Abdallah-Pretceille, La educación intercultural (Barcelona: Idea Books, 2001), 35.

5 Marco A. Borboa-Trasviña, "La interculturalidad: aspecto indispensable para unas adecuadas relaciones entre distintas culturas. El caso entre 'Yoris' y 'Yoremes' del centro ceremonial de San Jerónimo de Mochicahui, El Fuerte, Sinaloa, México”, Revista Ra Ximhai vol. 2, n. 01 (2006): 48. Disponible en: https://www.redalyc.org/pdf/461/46120104.pdf

6 Luis Enrique López y Wolfgang Küper, "La educación intercultural bilingüe en América Latina: balance y perspectivas", Revista Iberoamericana de Educación n. ${ }^{\circ} 20$ (1999): 44-48. https://rieoei.org/historico/documentos/rie20a02.PDF

7 Santiago Cueto y Walter Secada, "Eficacia escolar en escuelas bilingües en Puno, Perú", REICE. Revista Iberoamericana sobre Calidad, Eficacia y Cambio en Educación vol. 1, n. ${ }^{\circ} 1$ (2016): 3. https://revistas.uam.es/index.php/reice/article/view/5342. (05 de sep., 2019).

8 Luis Enrique López, "La educación bilingüe en Puno: hacia un ajuste de cuentas", en Educación bilingüe intercultural. Reflexiones y desafios, eds. Madeleine Zúñiga, Inés Pozzi-Escot y Luis E. López (Lima: FOMCIENCIAS, 1991), 173-217.

9 Saúl Bermejo Paredes, "Visión andina de la escuela oficial" (tesis de maestría en Lingüística andina y Educación, Universidad Nacional del Altiplano, 1992), 96. 
hacia la construcción de una "república con ciudadanos"10, y acceder plenamente a los derechos ciudadanos en mejores condiciones. Es más, en las últimas dos décadas, el movimiento indígena empezó a reinvindicar el derecho a la educación intercultural bilingüe asociado con la lucha por otros derechos como los territoriales, la defensa de los recursos naturales, culturales y lingüísticos, fundamentalmente.

Así, se postuló la EIB desde los pueblos indígenas como una aspiración de profunda transformación social y educacional; sin embargo, después de más de cuarenta años de ensayo e implementación en las escuelas rurales del ámbito regional de Puno, la EIB no ha contribuido significativamente en revertir la coyuntura primigenia. En la actualidad, según el Instituto Nacional de Estadística ${ }^{11}$, Puno conforma el segundo grupo de departamentos con tasas de pobreza entre $32,4 \%$ y $36,1 \%$, y pobreza extrema entre $7,7 \%$ y 9,8\%; además, precisa que al analizar los resultados a nivel de área de residencia, tanto en el área rural como urbana, la pobreza incidió en mayor proporción en la población cuya lengua materna es una lengua nativa (21,6\% en el área urbana y $44,8 \%$ en el área rural). Según los Censos Nacionales 2017: XII de población, VII de vivienda y III de comunidades indígenas ${ }^{12}$, el $42,9 \%$ de la población se autodefine como quechua y el $27 \%$ como aimara; juntas hacen más del $70 \%$. La educación en las zonas rurales de Puno está graficada en los siguientes datos: de cada cien estudiantes que inician el proceso de escolaridad, solo el $13 \%$ llega a concluir la educación superior ${ }^{13}$. Luego, al borde de una década, vuelven a corroborarse estos datos, así: Jaime Saavedra y Pablo Suárez ${ }^{14}$ establecen que, en Puno, de cada mil niños que inician sus estudios primarios, solo 773 terminan el 6.․ㅡ grado. La mayoría de ellos repiten el grado dos o tres veces antes de culminar la primaria.

Peor aún, desde la perspectiva de las poblaciones aimaras, la EIB afronta una grave crisis al considerársele como un proyecto racista y carente de interculturalidad, que conlleva a una inevitable autosegregación indígena. Esta situación ha llevado a plantear como problemática de estudio ¿cómo han sido los procesos de implementación de la EIB en la región de Puno a través de más de cuarenta años y cuáles son las percepciones que experimentan los usuarios aimaras con respecto a la EIB en las escuelas rurales para optar por una autosegregación? El objetivo del estudio es interpretar, desde la racionalidad aimara, cómo los procesos de educación intercultural bilingüe (EIB) desarrollados en las escuelas rurales de la zona aimara de Puno (Perú) generan como resultado, el fenómeno de la autosegregación indígena. Es un estudio desde "dentro", realizado por

10 Eloy Neira y Patricia Ruiz Bravo, "Enfrentados al patrón: una aproximación al estudio de las masculinidades en el medio rural peruano", en Estudios culturales. Discursos, poderes, pulsiones, eds. Santiago López Maguiña, Gonzalo Portocarrero, Víctor Vich y Rocío Silva (Lima: Red para el Desarrollo de las Ciencias Sociales en el Perú, 2002), 218.

11 Instituto Nacional de Estadística, "Encuesta Nacional de Hogares, 2016-2017. Informe Técnico: Evolución de la pobreza monetaria 2007-2017”" (Lima: INEI, 2018), 45-52.

12 Instituto Nacional de Estadística e Informática, "Perú: Perfil sociodemográfico. Informe Nacional. Censos Nacionales XII de población, VII de vivienda y III de comunidades indígenas" (Lima: INEI, 2018), 202.

13 Utta von Gleich, La educación bilingüe en Puno (Puno-Lima: GTZ, 1994), 78.

14 Jaime Saavedra y Pablo Suárez, Financiamiento de la educación pública en el Perú: el rol de las familias (Lima: GRADE, 2002$), 78$. Documento de trabajo n. ${ }^{\circ}$ 38. http://bibliotecavirtual.clacso.org.ar/Peru/grade/20100625014731/ddt38 
investigadores aimaras, con la participación de pobladores aimaras. Los resultados permitirán, entre otros aspectos, redefinir las concepciones provenientes de la racionalidad epistémica predominante y replantear las políticas de Estado respecto a la educación y la EIB, desde la visión y la racionalidad indígena aimara.

El abordaje del estudio transcurre bajo una metodología cualitativa-hermenéutica, que recurre a las técnicas del análisis documental y a las entrevistas en profundidad. El análisis documental consistió en el procesamiento analítico-sintético, la descripción y clasificación de las fuentes de información con el propósito de procesar, evaluar y sintetizar contenidos o mensajes en relación a un determinado contexto histórico social respecto a la problemática planteada. Las entrevistas en profundidad comprendieron principalmente a líderes comunales elegidos en asamblea comunal como presidente de comunidad (L) y padres de familia de instituciones educativas EIB, con cargo de presidente (F) representativos ${ }^{15}$, los mismos que corresponden a los ámbitos aimaras de Pichacani (P), Tolamarca (T), Soquesani (S), Ilave (I), Zepita (Z) y Kelluyo (K) del departamento de Puno. Los datos son inéditos, registrados (grabados y transcritos) mayoritariamente en lengua aimara, antes y después de las reuniones comunales y escolares para después ser codificados y clasificados según las categorías temáticas; fueron recogidos, en algunos casos, durante la década de 1990, por cuenta de la ejecución de una tesis de maestría ${ }^{16}$, y en otros, durante la movilización más resonante del pueblo aimara (en 2011) junto a un estudio ${ }^{17}$. Los resultados son producto de la metodología del análisis de contenido, con información sistematizada mediante el programa MaxQda.

\section{Resultados y discusión}

\section{Proceso diacrónico y sincrónico de la EIB en Puno-Perú}

En los albores del siglo XX, la presencia y condición indígena fue el pretexto para la marginación y la desigualdad social; la educación y el aprendizaje del castellano estaban prohibidos para los indígenas, se acuñaban frases como "indio leído, indio perdido", incluso intelectuales como el huancaíno Alejandro Deustua, refiriéndose a los indígenas, decía:

¿Qué influencia podrá tener sobre esos seres, que sólo poseen la forma humana, las
escuelas primarias más elementales? ¿Para qué aprenderán a leer, escribir y contar,
la geografía y la historia y tantas otras cosas, los que no son personas todavía,
los que no saben vivir como personas, los que no han llegado a establecer una

15 El criterio de representatividad, tanto de líderes como de padres, se definió en función al cargo de presidente (cargo máximo) alcanzado por consenso o elección en cada ámbito educativo o comunidad. Los personajes de ambos grupos participaron bajo consentimiento informado.

16 Bermejo, "Visión andina".

17 Saúl Bermejo Paredes y Yanet A. Maquera Maquera, "Interpretación de la escuela rural andina en comunidades aimaras de PunoPerú”, Revista Electrónica Educare vol. 23, n. ${ }^{\circ}$ (2019). https://doi.org/10.15359/ree.23-2.4. 
diferencia profunda con los animales, ni tener ese sentimiento de dignidad humana principio de toda cultura? ¿Por qué habrían de ser más felices, con esas ideas, que los más no podrán aplicar en su vida extraña a la civilización y de que algunos podrían hacer uso contra sus semejantes? Sólo un concepto intelectualista de la civilización puede concebir la felicidad en esas condiciones. ${ }^{18}$

Se trata de una coyuntura de gran polaridad e injusticia económica y social que, en Puno, estaba representada por los gamonales o terratenientes dueños de enormes extensiones de tierras (haciendas), que en alianza con el clero y la clase política local imponían un poder absoluto sobre los indígenas que despojados de sus tierras y derechos fundamentales estaban al servicio completo de sus opresores. Los gamonales sabían, desde sus antecesores que emprendieron la gran cruzada de la colonización occidental, que no podían abdicar y dejar en manos de los subordinados aquel símbolo e instrumento que tenía más poder de lo que ejercían: la escuela, que implicaría la reinversión del orden establecido. La idea de la reinversión escarapelaba por entonces a cualquier gamonal, por cuanto se asociaba a la memoria colectiva y resistencia ideológica presente en los pueblos sojuzgados desde la colonización, recreada a través de los mitos andinos como el del inkarrí ${ }^{19}$ (la conquista cercenó la cabeza del inca, desde ahí cuerpo y cabeza se encuentran separados; pero están creciendo y volverán a juntarse; entonces, renacerá el inca y volverá a gobernar), o el de la literatura pro indígena como "el sueño del pongo" ${ }^{20}$, cuya difusión en los textos escolares fue prohibida por los militares de la segunda fase de la "revolución peruana". Según el relato ofrecido por José María Arguedas, el pongo, el sirviente de las haciendas, sueña que su patrón tiene que lamerle excremento humano que han esparcido en su cuerpo. Este pensamiento respecto a la educación del indígena, se extendió conjuntamente con el sistema latifundista hasta 1969, año en que el Gobierno Revolucionario de las Fuerzas Armadas, presidido por Juan Velasco Alvarado, puso fin a los latifundios, transformando radicalmente la estructura agraria del país a través de la llamada Reforma Agraria $^{21}$.

En el período latifundista, si bien el concepto de interculturalidad estaba ausente, el primer antecedente de educación rural e intercultural bilingüe se registra con Manuel Z. Camacho en Puno, que de manera clandestina, desafiando el poder político-eclesiástico, cuando la escuela aún estaba prohibida para los indígenas peruanos, inició en 1904 la alfabetización para los aimaras, convirtiendo su casa en escuela, en la comunidad de Utawilaya-Ácora ${ }^{22}$. Aunque el objetivo de la escuela era la enseñanza del castellano, al parecer, para lograr

\footnotetext{
18 Alejandro O. Deustua Escarza, "El problema pedagógico nacional", en La escuela rural: Variaciones sobre un tema, ed. Carmen Montero (Lima: FAO-PEEC, 1990), 85.

19 Franklin Pease García Yrigoyen, "Las versiones del mito de inkarri”, Revista de la Universidad Católica n. 2 (1977).

20 Ezequiel Maldonado, “El sueño del pongo’ y la traducción de una cultura”, Fuentes Humanísticas año 28, n. ${ }^{\circ} 49$ (2014). http://hdl. handle.net/11191/5113

21 Alfonso Chirinos Almanza, "La reforma agraria peruana", Nueva Sociedad n. 21 (1975). https://nuso.org/media/articles/downloads/201_1.pdf

22 Saúl Bermejo Paredes, Hacia una educación intercultural. Crecer en un mundo plurinacional (Puno-Perú: San Valentín, 2010 ), 82.
} 
un mejor rendimiento en la escuela, también se utilizaba el aymara en forma instrumental $^{23}$. Esta experiencia sui géneris podemos situarla en la perspectiva de la interculturalidad crítica ${ }^{24}$, entendida como una propuesta de transformación social para afrontar el problema estructural-colonial-racial. Augusto Ramos, refiriéndose a Camacho, dice: "su preocupación era acabar con la ignorancia, que aprendieran por lo menos a leer y escribir, a hablar el castellano, para de esa manera enfrentarse en mejores condiciones a sus explotadores y poner fin al sinnúmero de abusos de que eran víctimas" ${ }^{25}$.

A este desafío de Camacho al sistema de orden imperante, y una población aimara cada vez más dispuesta a apropiarse de la educación y la escuela como estrategia de reivindicación social para sacudirse de la explotación, exclusión y racismo, se sumaron grandes intelectuales como: (a) El puneño José Antonio Encinas Franco, que concebía una escuela liberadora, sustentada en la pedagogía activa y la filosofía pragmatista ${ }^{26}$; propugnaba por una escuela que se convirtiera en el hogar del indio, con valor social e impulso político; antes de organizarse pedagógicamente, estableciendo planes de estudio, programa, horarios, etc., debía organizarse socialmente, creando en la aldea diferentes grupos para mejorar la agricultura, la crianza de animales domésticos, la arquitectura, la higiene pública y privada, el deporte, la danza, la música, las sociedades cooperativas de producción y de consumo, las de auxilio mutuo, las de la protección a la infancia, a la vejez y al enfermo ${ }^{27}$. Cuestionó que la educación se guiara de experiencias extranjeras, sin tomar en cuenta nuestra realidad social, dejando de lado el factor indígena; (b) Manuel González Prada ${ }^{28}$ sostuvo: "con las muchedumbres libres aunque indisciplinadas de la Revolución, Francia marchó a la victoria; con los ejércitos de indios disciplinados y sin libertad, el Perú irá siempre a la derrota. Si del indio hicimos un siervo, ¿qué patria defenderá?"; y (c) José Carlos Mariátegui, encuentra en la estructura agraria peruana las raíces de atraso de la nación y las razones de la exclusión de la vida política y cultural de las masas indígenas. Beige ${ }^{29}$ sostiene que Mariátegui concebía a la nacionalidad como un proyecto tendiente a integrar la memoria histórica y satisfacer las necesidades sociales de todos los habitantes del Perú.

23 David Ruelas, "Los movimientos indígenas y la educación del siglo XX en el sur andino puneño, peruano". Revista Historia de la Educación Latinoamericana vol. 21, n. ${ }^{\circ} 33$ (2019): 78. https://doi.org/10.19053/01227238.9354p.

24 Catherine Walsh, "Interculturalidad crítica y educación intercultural”, en Construyendo Interculturalidad Crítica (La Paz, Bolivia: Instituto Internacional de Integración del Convenio Andrés Bello, 2010). https://aulaintercultural.org/2010/12/14/interculturalidad-critica-y-educacion-intercultural/ (11 de setiembre, 2019). Walsh, refiere que la "interculturalidad crítica no existe"; no obstante, la experiencia desarrollada por Camacho en Puno, corrobora que es viable.

25 Augusto Ramos Zambrano, Aimaras rebeldes (Arequipa, Perú: Instituto de Estudios Pukara, 2007), 39.

26 Saúl Bermejo Paredes, Docencia y pedagogía de la educación bilingüe intercultural (Puno-Perú: ANAMEBI Perú-Región Puno, 2009), 4.

27 José A. Encinas Franco, Un ensayo de escuela nueva en el Perú (Lima: Editorial Minerva, 1932), 79-98.

28 Manuel González Prada, Páginas libres. Horas de lucha (Caracas: Biblioteca Ayacucho, 1976), 44.

29 Fernanda Beigel, "Mariátegui y las antinomias del indigenismo", Utopía y Praxis Latinoamericana año 6, n. ${ }^{\circ} 13$ (2001): 49. https:// produccioncientificaluz.org/index.php/utopia/article/view/2567/2567 
Durante el transcurso del siglo XX se registran las siguientes experiencias de educación intercultural en Puno ${ }^{30}$ : Daniel Espezúa Velasco, diseñó estrategias de enseñanza de la lectura y la escritura en lengua materna a principios de la década de 1930, en la ciudad de Juli, capital de la provincia de Chucuito; en la misma época (1935-1940), el maestro Alfonso Torres Luna elaboró material de enseñanza en aimara-castellano simultáneamente. Entre 1933 y 1940 se implementaron las Brigadas de Culturización Indígena, haciendo uso de las lenguas quechua y aimara con el fin de posibilitar la integración del indio a la civilización a través de programas socioeconómicos que mejoraran tanto su nivel cultural como sus condiciones de vida y trabajo, estimulando su reincorporación a la nacionalidad. En este marco, la experiencia de mayor impacto fue la desarrollada por María Asunción Galindo (1940-1951), en la escuela de Uxirani, convencida de que el niño indígena debía aprender a leer y escribir en su lengua materna; es más, criticó que hubiera un solo currículo para las escuelas rurales y urbanas. En 1945, bajo un convenio bilateral (Acuerdo de Warisata) entre Perú y Bolivia, se gestaron los Núcleos Escolares Campesinos (NEC); esta escuela - a diferencia de la tradicional-, no era para "civilizar" a los salvajes, a los indios, sino para incorporar a la vida del indio la cultura occidental, pero respetando y enriqueciendo sus diferentes manifestaciones culturales. En los NEC, la educación del niño indígena - refiere Pozzi-Escot ${ }^{31}-$, se volvió funcional con prácticas en los talleres y en el huerto, atendiendo a la crianza de los animales domésticos sin descuidar el estudio de asignaturas y el aprendizaje del castellano. El primer gran desarrollo de los NEC se produjo entre 1949 a 1956, período en el cual fueron dotados con generadores, proyectores, ómnibus, leche, semillas y tractores ${ }^{32}$. Para 1960 ya existían en toda la sierra 2416 escuelas centrales y satélites pero, lamentablemente, hacia 1972 los NEC habían dejado de operar y, con este suceso, la experiencia más valiosa en Puno de educación rural, con enfoque intercultural, colapsó de manera irremediable. El Acuerdo de Warisata puntualizaba que el problema del indio implicaba el problema de las masas de la población rural, que eran analfabetas y no sabían el castellano; la escuela rural debía detener la emigración; la escuela rural debía ser un factor catalizador para coadyuvar a la continuidad de las comunidades; en la escuela rural se debía enseñar en lengua vernácula primero y luego en español para posibilitar una mejor integración en la cultura occidental ${ }^{33}$.

Entre fines del sesenta y comienzos del setenta del siglo pasado, surgieron en Puno como experiencia educativa inédita, los wawa-uta y los wawa-wasi dirigidos a niños aimaras y quechuas pre-escolares que marcaron el nacimiento de la Educación Inicial en el Perú. López y Jung ${ }^{34}$ apuntan que fueron organizados

\footnotetext{
30 Bermejo, Hacia una educación, 65.

31 Inés Pozzi-Escot, "Balance y perspectivas de la educación para poblaciones indígenas en el Perú", Allpanchis vol. II, n. ${ }^{\text {os }} 35 / 36$ (1990).

32 Nancy H. Hornberger, Haku Yachaywasiman: la educación bilingüe y el futuro del quechua en Puno (Lima-Puno: Programa de Educación Bilingüe en Puno, 1989), 65.

33 Teresa Valiente Catter, "Historia social, historia local y educación bilingüe", Allpanchis vol. II, n. ${ }^{\text {os }} 29 / 30$ (1987).

34 Luis E. López e Ingrid Jung, Las lenguas en la educación bilingüe. El caso de Puno (Lima: GTZ, 1988).
} 
con el fin de prestar atención a los niños de edad pre-escolar del ámbito rural, y concebidas de manera tal que se los aprestara para su ingreso a la escuela, lo que de por sí suponía su iniciación en el castellano. En 1972 se emitió la Política Nacional de Educación Bilingüe (PNEB) como un hecho sin precedentes en el Perú y en la región latinoamericana. Era la primera política que respondía oficialmente a la diversidad étnica, cultural y lingüística del país.

En este marco, en 1975, bajo un convenio bilateral entre Perú y Alemania, surge el Proyecto Experimental de Educación Bilingüe de Puno (PEEB-P) ${ }^{35}$, iniciando sus actividades en 1977 bajo el modelo de transición, para después optar por el modelo o programa de educación bilingüe de mantenimiento. Es considerado como la mayor experiencia de educación bilingüe, especialmente en la producción de materiales educativos. Bolivia y Ecuador definieron sus políticas de educación bilingüe en función al modelo puneño ${ }^{36}$ : los textos de castellano producidos en Puno fueron adaptados al contexto ecuatoriano y reimpresos en dicho país; el caso de Bolivia fue más amplio y significó una autorización para adecuar todos los materiales educativos en quechua, aimara y castellano. El PEEB-P transitó por tres fases: Iniciación (1977-1980), en la cual se desarrollaron investigaciones de base para formular currículos, estrategias y contenidos; se diseñaron y elaboraron los primeros libros de texto. Implementación (1980-1988), con diversas actividades para asegurar el trabajo en aula de la educación bilingüe. Consolidación, iniciada en enero de 1989 para apuntalar la experiencia y corregir las deficiencias. El PEEB-P concluyó sus actividades en 1990. En enero de 1991, en el evento denominado "Puno: Cien escuelas para dos lenguas", se hizo entrega del proyecto al Ministerio de Educación del Perú y al Gobierno de la Región José C. Mariátegui de Puno. El cese de las acciones del PEEB-Puno, en plena etapa de generalización, marcó el colapso de la educación bilingüe en toda la zona andina del país. Entre algunos de los factores que marcaron el colapso del PEB- $\mathrm{P}^{37}$ se pueden anotar: personal especializado no disponible, problemas financieros, maestros poco comprometidos, rechazo por parte de los usuarios, escuela-isla en la comunidad, seguimiento y asesoramiento débil, cambio constante de personal docente, adaptación y no construcción del currículo, y la indiferencia del Estado, que no asumió la institucionalización de la educación bilingüe.

La primera década del siglo XXI, en lo que se refiere a la EIB en el país, transcurrió a nivel de simple enunciación en políticas y leyes. Esta década marcó un retroceso en las políticas de educación intercultural dirigidas a poblaciones indígenas. Así, para el 2006 se ofrecía involucrar al 50 \% de la población escolar indígena bajo la EIB, y para el 2015, la EIB llegaría a cubrir el $100 \%$. Pero la realidad fue otra; en el 2004, los datos oficiales de la Dirección Nacional de Educación Bilingüe Intercultural (DINEBI) indicaban que, con el programa EBI, únicamente

35 Bermejo, Hacia una educación, 92-95.

36 López, «La educación bilingüe en Puno".

37 Saúl Bermejo Paredes, “La educación bilingüe en Puno. ¿Una historia del fracaso?”, Revista Investigaciones en Ciencias Sociales vol. 2 (1994). 
se había atendido al 27 \% de la población rural bilingüe. La DINEBI fue despojada de su rango y simplemente pasó a constituir una unidad administrativa de la Dirección General de Educación Intercultural Bilingüe y Rural (DIGEIBIRA), denominada Dirección de Educación Intercultural Bilingüe (DEIB), sin ninguna atribución normativa y siempre dependiente de la alta dirección, el ministro y los viceministros de Gestión Pedagógica y Gestión Institucional. Es más, para el 2007, los discursos sobre interculturalidad, la atención a la diversidad, así como lo establecido en el Acuerdo Nacional (2002), la Ley de Bases de la Descentralización n. 27783 (2002), la Ley General de Educación n. 28044 (2003) y el Proyecto Educativo Nacional, quedaron, en términos generales, en simples enunciaciones.

A pesar de una coyuntura adversa, en Puno como vanguardia de la EIB se registran los siguientes hechos: a) El intento de construir socialmente un programa curricular EIB por el Proyecto Nueva Educación Bilingüe Multicultural en los Andes ${ }^{38}$, promovido por CARE Perú (2002-2005) en cinco escuelas de Azángaro; b) Entre 2005 y 2007 desde la Dirección Regional de Educación Puno (DRE-P), liderados por el docente Saúl Bermejo Paredes (Director DRE-P), se formularon dos proyectos referidos a la educación intercultural en Puno: 1. El Proyecto Educativo Regional (PER-Puno), elaborado en el 2005 como síntesis de las audiencias públicas en cada una de las trece provincias de Puno, entró en vigencia a partir del 2007-2015, a través de la Ordenanza Regional n. ${ }^{\circ}$ 010-Gobierno Regional de Puno y ampliado posteriormente con la Ordenanza Regional n.. 012-2016 hasta el 2021, respectivamente; 2.. El Proyecto Curricular Regional de Puno (PCR) ${ }^{39}$ construido socialmente a través del Consejo Participativo Regional, bajo los enfoques EIB y las teorías cognitivas, constructivistas y socioculturales; apostó básicamente por una educación descolonizadora que coadyuvara a la transformación social, asegurando una educación de calidad, equidad y pertinente al contexto sociocultural lingüístico. El PCR fue entregado por la DRE-P en mayo de 2007 al Gobierno Regional de Puno, para implementarse a partir de 2008 en respuesta al cuarto objetivo estratégico del PER-P; no obstante, por la inadecuada implementación administrativa-pedagógica-presupuestal y por la injerencia de factores externos como CARE Perú/Puno, para el 2013 ya había perdido vigencia, sentido y esencia, convirtiéndose en un programa dedicado a la folclorización de la cultura, lengua, sabiduría y conocimientos de los pueblos aimara y quechua.

Actualmente, al finalizar la segunda década del siglo XXI, las políticas públicas con respecto a la educación en el Perú, están definidas en el Proyecto Educativo Nacional (PEN 2007-2021), que paradójicamente, en ninguno de sus objetivos estratégicos hace referencia explícita a la educación intercultural; excepcionalmente, en el 2016, a través de la Resolución Ministerial n. ํㅜ 629-2016MINEDU, se aprobó el Plan Nacional de Educación Intercultural Bilingüe al

38 Nueva Educación Bilingüe Multicultural en los Andes-EDUBIMA-CARE Perú, Una experiencia de construcción curricular participativa Azángaro-Puno (Lima: CARE-Perú, 2007), 95.

39 Saúl Bermejo Paredes, “Los mejores y últimos... ¿El PCR una realidad o un imaginario?”, Los Andes, Puno, 11 de agosto, 2013, 8-9, http://losandes.com.pe/oweb/Cultural/20130811/73891.html (29 de agosto, 2019). 
$2021^{40}$. Este plan se encuentra actualmente en pleno proceso de consulta previa y pretende: Implementar la educación intercultural bilingüe en las más de veintiún mil instituciones educativas de EIB registradas como tales, con todos los componentes de calidad que se requieren: docentes bilingües formados y titulados, implementación de un currículo y propuesta pedagógica de EIB, dotación y uso adecuado de materiales educativos en lenguas originarias y en castellano, y desarrollo de una gestión moderna y participativa; en Puno carecemos de propuestas que estén viabilizando la EIB con vitalidad, equidad y calidad. La educación puneña actual, dirigida a las poblaciones quechua y aimara, no dista mucho de la educación del siglo pasado, en este sentido: las frases de Tamayo Herrera $^{41}$ cobran plena vigencia cuando manifiesta que la historia de la educación puneña, durante el siglo XX, es la historia del ensayo, del fracaso y de la desorganización más absolutas; como señalan Alanoca y otros ${ }^{42}$, para la nación aymara la educación tiene una connotación y un significado de transformación, por ello se han creado estrategias de lucha para el acceso a la educación formal, el cual no fue respondido de manera pertinente.

\section{Autosegregación indígena}

Los procesos de colonización etnocentrista y la imposición secular de la cultura dominante en Puno, trajeron como consecuencia el menosprecio por las culturas aimara-quechua y la negación del valor humano de sus habitantes. Hacer que alguien no exista o no tenga valor como ser humano ${ }^{43}$, constituye una práctica mortificante, un desprecio a la vida y condición humana que desborda incluso el campo semántico de lo que se entiende por discriminación y racismo. Ante el hecho de "no valer nada", el saber leer y escribir a través de la escuela se configuraron como los bienes más preciados para acceder al saber civilizatorio occidental $^{44}$ y recobrar el respeto y la dignidad humana-indígena. El respeto ${ }^{45}$ es radical y concierne a todo ser humano, sin que esté supeditado a un estatus económico, político, pertenencia cultural o reconocimiento social; el respeto permite que todo y todos sean a plenitud lo que tienen que ser, hace que la vida se viva con emoción y sentido, fructifica el talento individual y social; y, regula la existencia misma y la armonía hombre-universo ${ }^{46}$.

40 Ministerio de Educación del Perú, “Plan nacional de educación intercultural bilingüe al 2021” (2016): 21, http://repositorio.minedu. gob.pe/handle/123456789/5105 (05 de setiembre, 2019).

41 José Tamayo Herrera, Historia social e indigenismo en el altiplano (Lima: Ediciones Treintaitrés, 1982).

42 Vicente Alanoca, Ofelia Mamani y Wido Condori, "El significado de la educación para la nación Aymara", Revista Historia de la Educación Latinoamericana vol. 21, n. ${ }^{\circ} 32$ (2019): 243. https://doi.org/10.19053/01227238.6994

43 Afirmar que los indios solamente tienen la forma humana, no solo fue el pensamiento de Alejandro Deustua, como ya se vio, sino de la república aristocrática del siglo pasado.

44 La mentalidad colonial hizo consentir que lo occidental representaba al mundo civilizado, por tanto, superior, y lo andino o indígena simplemente constituía el mundo de los salvajes o seres inferiores.

45 Juan Carlos Godenzzi, "Introducción / Diversidad histórica y diálogo intercultural. Perspectiva latinoamericana”. TINKUY, Sección de Estudios Hispánicos n. ${ }^{\circ} 1$ (2005), 8. https://dialnet.unirioja.es/descarga/articulo/3302998.pdf.

46 Saúl Bermejo P. y Yanet A. Maquera M., "Aimaras de Puno y la actitud minera: ¿para llegar a la vida hay que pasar por la muerte?”, Revista de Investigaciones Altoandinas vol. 18, $\mathrm{n}^{\circ} .1$ (2016). doi: http://dx.doi.org/10.18271/ria.2016.180. 
Jani iskuyla saririxa, janiwa kawkitpachsa jaqijama, uñtatakiti (T-L-3) ${ }^{47}$ (El que no va a la escuela, desde siempre, no es visto como ser humano); qamiri, wäli jach'a uraqini, misti jaqinakasti, jiwasanakaruxa ch 'iñintayata, jani manq'ani, janisa jaqiksnati, ukhamwa asintanakapanxa jakawaytanxa. Ukapti, iskuylanxa ulliri, qilqiri wäli yatiqañawa, jani ukhama jakaña uñjasiritaki (S-L-5) ${ }^{48}$. (En las haciendas, los gamonales nos tenían con liendres, sin comida, como si no fuésemos personas humanas. Por eso, para no vivir así, es muy necesario aprender a leer y escribir en la escuela). Concordando con Montoya, ser "leído" representa "tener ojos, salir del mundo de la noche para ver la luz, el día"49; en cambio, el que no sabe leer y escribir vive en el mundo de la oscuridad, en el de los gentiles, y no tiene ojos que son decisivos para conocer y actuar.

Guamán Poma de Ayala creía que con la instrucción se garantizaba buenos dirigentes y buenos defensores del pueblo; veía en la educación una posibilidad de formar buenos líderes sociales que asumirían un buen gobierno en defensa de los indígenas, estableció - citado por Maguiña ${ }^{50}$ - que, "quienes gobernasen deberían formarse ladinos y para ello se ha de criarse cristiano ladino y, si pudiese sepa latín y leer, escribir, contar y sepa ordenar peticiones y interrogatorios para defensa de sus personas y de sus indios y sujetos, vasallos, pobres de Jesucristo". Analógicamente, lo mismo podemos decir de Garcilaso, Santa Cruz Pachacuti, de los hijos de los caciques, o de los indígenas que comandaron la revolución de Túpac Amaru II, Túpac Katari, porque fueron indígenas leídos e intelectuales. En la siguiente historia que escribió Garcilaso de la Vega ${ }^{51}$, se revela el poder de la escritura y la educación. Garcilaso relata sobre unos indígenas enviados por un capataz a donde estaba el amo con una carga de melones y una carta; fueron advertidos respecto a que no faltase ningún melón, de lo contrario la carta los delataría. Para evitar ser delatados escondieron la carta tras de un paredón y probaron algunos melones. La sorpresa fue increíble cuando llegaron a su destino, el amo al leer la carta descubrió el faltante de la carga. Los indígenas salieron maravillados de este hecho, dijeron que con mucha razón llaman dioses a los españoles, con el nombre de Wiraqucha, pues alcanzaban tan grandes secretos y poderes. Realmente la educación y la escritura son poderosas, y quienes acceden a ellas, según algunos mitos, se elevan a la condición de dios supremo, Wiraqucha.

El mito dio paso a la práctica cuando, en muchos lugares, los propios aimaras, un adobe tras otro, levantaron sus escuelas y pagaron a los maestros con sus propios recursos. "Tomás Cutipa ha dado su terreno para levantar en ahí la escuela. Después nosotros mismos con el patronato hemos pagado al profesor que enseñaba. En ahí, todos han aportado para escuela, después volvió fiscal

\footnotetext{
47 Líder-Presidente, Comunidad Campesina Tolamarca.

48 Líder-Presidente, Comunidad Campesina Soquesani.

49 Rodrigo Montoya, Por una educación bilingüe en el Perú. Reflexiones sobre cultura y socialismo (Lima: CEPES/Mosca Azul Editores, 1990), 92.

50 Alberto Maguiña, "La voz de Felipe Guamán Poma de Ayala”. Autoeducación. Revista de educación popular n. 32 (1991), 46.

51 Inca Garcilaso de la Vega, Comentarios reales de los incas, tomo II, segunda edición (Buenos Aires: EMECÉ editores, 1943), 276-277.
} 
$(\mathrm{T}-\mathrm{F}-3)^{52 \prime}$. Estas actuaciones se generalizaron en gran parte de las comunidades que aspiraban a tener una escuela como símbolo de progreso en contraposición a la situación de atraso; son además las primeras experiencias de apropiación y autogestión de elementos culturales foráneos. Las comunidades aimaras, antes que el Estado, fueron las primeras en autogestionar y administrar la escuela bajo sus propios mecanismos de organización social y política comunal. La noción de progreso está directamente relacionada con la idea de tener una escuela, y la de atraso implica quedarse en el campo, "quedarse igual que nosotros". Iskuylxa, wawanaka laykuwa muntanxa, jani jiwasanakjama pampana qhipaktata uñjasiñapataki $(Z-F-11)^{53}$. (Anhelamos la escuela por el bienestar de nuestros hijos, para que no acaben como nosotros en el campo). Las escuelas autogestionarias, vistas como señal de progreso, fueron convertidas a escuelas estatales por iniciativa de los mismos que las crearon, y desde ese momento, abdicaron todos sus intereses e ideales entregándoselos a las manos del Estado.

De una organización participativa, consensuada y comunitaria, ahora la escuela desde el Estado se torna impositiva y autoritaria ${ }^{54}$. Este desenlace acabó generando en las comunidades indígenas, ideas y actitudes, no resueltas hasta hoy, de rechazo y atracción por la escuela. Juan Ansión ${ }^{55}$ señala que, para el campesino, sus hijos son su futuro y ese futuro tiene que pasar necesariamente por la escuela, generándose entonces estrategias de corto y largo plazo que terminan en una actitud ambivalente (repulsión y atracción), respecto a la escuela. Anatmayakwa, anatt'asipkixa, ¿kunawrasasa yatiqapxpachaxa? (Solo juegan y juegan, ¿en qué momento aprenderán?). Wäli luririnawa, jichhasti iskuylana qillaptatakixiwa $(\mathrm{P}-\mathrm{F}-8)^{56}$. (Era muy trabajador, ahora en la escuela se ha convertido en un flojo). Qullqimayakwa kunatakisa wayt'asiskixa (P-L-10) ${ }^{57}$. (Por cualquier asunto, solo te exigen dinero). Achachixiwa, jichhamarawa tukyjxani ¿kunpuni yatiganchi? (Z-F$2)^{58}$. (Ya está maduro, este año termina ¿qué habrá aprendido?).

Para unos, se desea una escuela conectada con las necesidades, problemas, formas de vida, de pensamiento, comunicación y de aprendizaje practicadas en la comunidad, permitiendo a los maestros y alumnos contribuir a la integración de conocimientos, capacidades y actitudes que, finalmente, promuevan el bienestar colectivo. Los padres se pronuncian: "Que los profesores impartan a nuestros hijos conocimientos técnicos agropecuarios para el desarrollo de nuestras comunidades". Enseñen cómo criar bien más mejor ganado, hacer buena chacra. Siquiera jabón harían, coser su ropa, zapato harían, eso sería bueno..." ${ }^{59}$. Por su

\footnotetext{
52 Presidente Asociación Padres de Familia, Comunidad Campesina Tolamarca.

53 Presidente Asociación Padres de Familia, Distrito Zepita.

54 Bermejo, "Visión andina", 76.

55 Juan Ansión, La escuela en la comunidad campesina (Lima: Proyecto Escuela, Ecología y Comunidad Campesina, 1988 ), 78.

56 Presidente Asociación Padres de Familia, Distrito Pichacani.

57 Líder-Presidente Comunidad-Distrito, Pichacani.

58 Presidente Asociación Padres de Familia Zepita.

59 Rimanakuy-Cusco 1986. Conversatorio regional de comunidades campesinas del Sur-Este 1986 (Cusco: Editorial Sur, 1986), 275.
} 
parte, los profesores, con el apoyo de algunos organismos en favor de la escuela en contextos rurales, dicen:

Lo que se enseña teóricamente debe ser llevado a la práctica. Los campesinos quieren ver resultados concretos, no toleran mucha palabrería. Es hora de hacer de la escuela una institución activa y funcional, con savia de comunidad y aliento de progreso capaz de formar hombres libres, promotores conscientes siempre dispuestos al trabajo productivo, sin abdicar de su hogar ni de su comunidad. ${ }^{60}$

En este vaivén de posiciones y definiciones sobre el valor de la educación y la escuela, se apela a la interculturalidad y la educación intercultural desde el mundo de los académicos, ONG, y desde el propio Estado, como incorporación del reconocimiento de la diversidad lingüística-cultural y las identidades excluidas en los procesos pedagógicos para pretender la calidad y equidad educativas. Incluso, el surgimiento de los movimientos indígenas nacionalistas identitarios que enarbolaron el derecho natural de ser pueblos y naciones, la libre determinación y la autonomía territorial, también hacían suyo que en la educación debían emplearse las lenguas indígenas para que los niños aprendieran mejor. UNCA ${ }^{61}$ taypinxa sapxiwa: aymara arutxa, wawanakasasa jilpachwa yatiqapxaspaxa. (En el UNCA dicen: nuestros hijos aprenderían mucho mejor en la lengua aimara). Las experiencias de Educación Intercultural Bilingüe (EIB), conducidas en Puno por las ONG (GTZ-alemán y CARE Perú), y por el Estado coincidentemente, señalaban haber logrado en los niños la comprensión de lectura y razonamiento matemático y el manejo oral y escrito de la lengua materna y del castellano, prioritariamente y los elogios no faltaban: "Reconocemos que la cooperación internacional y las ONG tienen éxito en su gestión de proyectos como es el caso de CARE Perú... los pueblos no deben ser considerados como "beneficiarios", sino como "actores", el PCR Puno testimonia este estilo de trabajo" 62 .

Empero, simplemente el paso del tiempo (más de cuatro décadas) se ha encargado de develar que las políticas de EIB en Puno no han respondido a las expectativas de sus usuarios ni han logrado concretar sus propósitos. Los informes y balances presentados a las instancias oficiales del Estado, a las organizaciones financieras, en los espacios académicos, publicaciones y otros, dando cuenta de las ventajas y bondades de una educación intercultural bilingüe, se han desmoronado por sí solos ante la evidencia irrefutable de constatar que los beneficiarios de la EIB, por su condición indígena, permanecen, inevitablemente, en situaciones de discriminación, exclusión e inequidad. Gabriela Guerrero, al presentar los resultados de su estudio en Puno, afirma con contundencia que,

\footnotetext{
60 Centro Peruano de Estudios Sociales, La educación rural en el Perú: Opinan los maestros (Lima: CEPES, 1989), 203.

61 Unión Nacional de Comunidades Aimaras (UNCA).

62 Dirección Regional de Educación Puno/CARE Perú, Proyecto curricular regional de Puno. Sistematización de su proceso de construcción. Construcción social emergente de afirmación cultural y desarrollo (Puno-Perú: Edit. Altiplano EIRL, 2011), 103.
} 
EBI quechua y EBI aimara tienen un efecto negativo y estadísticamente significativo en el rendimiento de los alumnos tanto en matemática como en comprensión de lectura [...] Los estudiantes EBI aimara obtienen en promedio 3,4 puntos menos en matemática y 2,4 puntos menos en comprensión de lectura cuando se los compara con sus pares en otros tipos de escuela. ${ }^{63}$

Cueto y Secada ${ }^{64}$, después de haber implementado un trabajo de investigación en 28 escuelas rurales de Puno, interpelan seriamente a los tomadores de decisiones por afirmar que, luego de treinta años de instaurado el programa EBI, esté completamente operativo, sentenciando: "Pueden al mirar los resultados descritos aquí, concluir que el programa no funciona"; añaden que los estudiantes en escuelas EBI no logran los mejores rendimientos, que los estudiantes en escuelas rurales monolingües en español en los mismos contextos. Como remate, Zúñiga y Gálvez ${ }^{65}$ afirman que la implementación de la EBI ha sido bastante limitada y, lo más grave es que no ha logrado mayor aceptación de los actores educativos; no ha influido en los programas curriculares para población rural, menos para escuelas urbanas y no tiene presencia en la sociedad nacional.

Los defensores de esta EIB seguramente dirán que no se puede determinar el fracaso de la EIB solo a partir de los resultados en los aprendizajes; sin embargo, cabe aclarar que no ha fracasado la EIB sino la pretensión y el trasfondo diseñado de lo que se hizo consentir mediáticamente como EIB. Los usuarios no son los que subestiman el valor de la EIB, sino sencillamente, concuerdan con los hechos que les toca vivir. Iwi iskuylanxa, sapxana: purapa arutwa yatiqt 'apxata, ukhamatwa, janiwa khitisa qhiparuxa jisk'achchitaniti. Jichhurusti iukhamati? Aka tawaqu, waynanaka wäli tarwjuniti?, suma ist'ata maq't'ati? ¿mach'aña jakañsti janiti uñt'xapxi? (I-L-2) ${ }^{66}$. (En la escuela EBI decían: aprenderán en dos lenguas, y así nadie podrá menospreciarlos. Hoy en día ¿esto es así? Estos jóvenes ¿tienen un buen trabajo?, ¿tienen buena ropa y comida?, ¿dejaron de vivir en condiciones precarias?). Aymarata arsuñani, nayra achachilanakasjama isisiñani, sapxiwa. Ukhamasinxa, khitiraki ¿yäqchituxa? ¿khitinakatakisa ukhamanakxa lurtanxa? (K-L-1) ${ }^{67}$. (Hablemos en aimara, vistámonos como lo hacían nuestros abuelos, dicen. Al actuar de ese modo ¿quién nos valora?, ¿para quiénes hacemos todo esto?). Estas expresiones interpelan seriamente las teorías y posturas admitidas como interculturales en la educación.

Se deja ver a trasluz que, en realidad, se usó y abusó del término intercultural y de la educación intercultural para justificar la presencia indígena y como pretexto para encubrir la marginación y la exclusión que son estructurales e

63 Gabriela Guerrero, "Del dicho al hecho hay mucho trecho. Un análisis de la implementación de la política nacional de educación bilingüe intercultural en Puno", en Cambio y continuidad en la escuela peruana: una mirada institucional a la implementación de programas, procesos y proyectos educativos:, eds. Martín Benavides y Paul Neira (Lima: GRADE, 2010), 87.

64 Cueto y Secada, "Eficacia escolar en escuelas bilingües", 19.

65 Madeleine Zúñiga y Modesto Gálvez, "Repensando la educación bilingüe intercultural en el Perú: bases para una propuesta de política", en Interculturalidad y politica: desafíos y posibilidades, ed. Norma Fuller (Lima: Red para el Desarrollo de las Ciencias Sociales en Perú, PUCP-UP-IEP, 2002), 21.

66 Líder-Presidente multicomunal, El Collao-Ilave.

67 Líder-Presidente Comunidad, distrito Kelluyo. 
históricas para las comunidades aimaras e indígenas en el Perú. El montaje de la EIB no tiene cabida para nosotros los aimaras mientras subsistan las asimetrías y relaciones de poder que, en lugar de ceder, acentúan la injusticia cognitiva, económica y la desigualdad social. Jiwasa taypinxa, uka aru intirkulturala janiwa utjkiti. Jupanakawa, kawkitpuni apanipchi (S-L-1) ${ }^{68}$. (Entre nosotros, la palabra intercultural no existe. Ellos, trajeron no sé de dónde). Si, las nociones de interculturalidad y educación intercultural no corresponden a las poblaciones indígenas, es lógico entonces que se trate de una educación impuesta. Aymarasa, kastillanusa ukhampurakiniwa sasawa sapxana. Jichhuruxa janiwa ukhamakiti, kastillanurakisa kawkinsa k'atampi jila waluranixixa, aymara arsuriraki jisk'achata $(\mathrm{Z}-\mathrm{F}-3)^{69}$. (El aimara y el castellano serán lenguas de igual jerarquía, decían. Hoy no es cierto, el castellano es el que tiene mayor valor donde sea, y el hablante aimara es menospreciado). Sin duda alguna, el mayor valor de la EIB consiste en propiciar el castellano estándar, que al mismo tiempo representa estatus, poder en sus variadas dimensiones, entonces, ¿dónde queda el respeto y el diálogo intercultural, cuando la EIB no ha suprimido la situación de diglosia o el poder/ hegemonía que ostenta el castellano? Es improbable que el español confiera o ceda su hegemonía, por ahora, es más, es el único idioma a través del cual se ejerce ciudadanía y se participa en la vida del país.

Si la EIB no se interesa en develar las causas de la dominación, inequidad y exclusión, entonces ¿se trata de una trama para impedir el encaramiento de la colonialidad del poder $?^{70}$, ¿es una estrategia para impedir reparar las injusticias cometidas con los "nadies", que por su condición indígena no hacen ciencia sino hechicería, hablan dialectos y no idiomas, no desarrollan cultura sino folclore, pertenecen a etnias y no a naciones y solo aparecen en las estadísticas como pobres y extremos pobres, únicamente? Los aimaras sentimos y pensamos que las respuestas son negativas, en todos sus extremos. Se constata de manera reiterativa entre la población aimara, los señalamientos de la EIB como un programa racista y discriminatorio. ¿Kunatsa markanakanxa jach'a iskuylanakanxa, aka kampunjamxa paya aruta kastillanuta ukhamaraki aymaratsa jani yatichapxpachaka? Puwrïstanxaya, kampu jaqikiwa sapxchixzaya, ukatxaja munstansa janisa, jiwasanakatakmaya akhama iskuylxa apayanipxchixa (P-L-1) ${ }^{71}$. (¿A qué se debe que en las grandes ciudades y escuelas no enseñan en dos lenguas como el castellano y el aimara, como sucede aquí, solo en el campo? Dirán que solo somos unos pobres campesinos y que por esta nuestra condición nos imponen esta escuela).

También está corroborado que, como producto de haber incorporado la educación intercultural bilingüe en las escuelas rurales pertenecientes a los territorios aimaras, por versión coincidente de los diferentes informantes se constata que cada vez más niños, con el paso de los años y grados de estudios, dejan de ser hablantes aimaras, asimilándose al castellano. Iskuylanxa, wawanakasaxa

\footnotetext{
68 Líder-Presidente Comunidad Soquesani.

69 Presidente Asociación Padres de Familia, Zepita

70 La colonialidad del poder es una categoría conceptual sostenida por Aníbal Quijano.

71 Líder-Presidente Comunidad, Pichacani.
} 
pisikwa aymaratxa qillqapxisa, jilaprtixa kastillanutkamwa arsusipxisa, qillqapxisa. Nanakatakisa ukaxa, walikiskiwa (A-P-5). (En la escuela, los niños leen poco en aimara, la mayoría habla y escribe en castellano. Eso está bien para nosotros). Aka iskuylanxa, purapa arutwa ullanisa, qillqanisa sapxanawa. Janjamakiwa ukhamakiti, kunatsti imilla yuqallanakaxa aymarata arsuñxaa jask'arapxiwa (T-L-1) ${ }^{72}$. (Prometieron que en la escuela leerían y escribirían en ambas lenguas. Creo que no es así, por cuanto las niñas y los niños sienten miedo para expresarse en aimara). La zona aimara de la provincia de El Collao-Puno, es, en la actualidad, bastante ilustrativa en este sentido: los niños en las escuelas más alejadas de los centros urbanos (frontera con las regiones de Tacna y Moquegua), así como sus docentes, usan predominantemente el castellano en diferentes situaciones comunicativas; en cambio, en las escuelas próximas a las ciudades, aún existe alternancia entre el uso del aimara y del castellano, dependiendo de las situaciones y contextos de comunicación. Este fenómeno lingüístico era contrario hace tres o cuatro décadas. Estudios como el de Cueto y Secada ${ }^{73}$ coinciden en señalar que el uso del español es más frecuente en los últimos grados, sugiriendo un modelo de asimilación al español que se acentúa con el tiempo. Los estudiantes y los padres de familia en escuelas EBI valoran menos el aprendizaje de la lectura y la escritura en aimara. De esta manera, la educación intercultural bilingüe en Puno (a lo largo de décadas de experiencia), ha contribuido al fortalecimiento de la diglosia y al consiguiente desplazamiento lingüístico del aimara.

Ante esta situación, la autosegregación aimara aparece como una estrategia para mantener vivas la cultura y la lengua aimara, evitando su lenta y paulatina desaparición. Iskuylaxa k'achata k'achata aymara arusxa chhaqhayxaniwa (P-L$1)^{74}$. (Paulatinamente la escuela habrá desaparecido nuestra lengua aimara). Jani aymara arusa walisiyxapchiti uka, chhaqhayaña munxapchi ukaxa, jiwasanakaya wasitata machaqa iskuyla utt'ayañani, jani jupanakata t'aqakt'asisna (I-L-2). (Si no le otorgan el valor a nuestra lengua, si pretenden desaparecerla, entonces nosotros nuevamente sentemos las bases de una nueva escuela, sin buscar separarnos de ellos). La autosegregación indígena aimara no consiste en el aislamiento del mundo o en pretender una separación territorial del país. Es comprendida como la construcción de un nuevo contrato social, de nuevas relaciones sociales basadas en el respeto y el crecimiento de la identidad (diferencia) como pueblo indígena aimara, para abrir espacios democráticos, participativos y consensuados, y poder participar plenamente en la vida social y política del país. Iskuyla taypinxa, uñtatawa maratsa, maratsa aymara arusa jaytamukutakxiwa, chhaqxirjamaxiwa. Ukatpi jisawanakaxa ch'amanchañanixa jani chhaqhañapataki, aymara arutxa arsusipxapuniñani (I-F-3) ${ }^{75}$. (Es sabido en la escuela que, año tras otro, el uso del aimara va quedando relegado. Está en camino a la extinción. Por eso nos corresponde hacer esfuerzos para que no desaparezca, comuniquémonos siempre en aimara).

72 Líder-Presidente Comunidad, Tolamarca.

73 Cueto y Secada, "Eficacia escolar en escuelas bilingües", 16-19.

74 Líder-Presidente Comunidad Pichacani.

75 Presidente Asociación Padres de Familia, Ilave. 
En materia educativa, los pueblos aimaras pretenden llegar a definir sus propios propósitos educativos sin desvincularse de la sociedad nacional y mundial bajo el marco del principio ético del respeto. Esto implica que la interculturalidad y la educación intercultural bilingüe deben ser para todos, el respeto y el reconocimiento de los pueblos indígenas no puede darse como consecuencia automática del tratamiento de la diversidad a nivel cognitivo o informativo, únicamente.

Las formas de pensamiento, ciencia y tecnología desarrolladas durante milenios por nuestros pueblos prehispánicos deben ser conocidas y valoradas como aportes para la humanidad entera; el mundo del siglo XXI no puede darse el lujo de ignorarlos o subestimarlos. Janiwa t'aqaktañatakiti, aymaranakjamaxa, chiqanxa munapxta, wäli ch'amacht'aña yaqha p'iqt'irinakampi, yaqhatuqi markanakampi suma aka jani wali jakawissa kuttáysna, suma jaqkama utjañataki (K-L-1) ${ }^{76}$. (No es para separarnos, como aimaras pretendemos hacer alianzas estratégicas con otros líderes, pueblos, para revertir nuestra situación y poder vivir como seres humanos). En un país plurinacional de todas las sangres, la autosegregación indígena aimara se comprende entonces, como un proyecto ideológico-cultural basado en el respeto y los principios democráticos, que busca consolidar una fuerza más dialogante y horizontal de transformación real de nuestra sociedad para llevar una vida con dignidad.

La autosegregación indígena aimara se sustenta en una epistemología ${ }^{77}$ particular, distinta al paradigma predominante de vida lineal y progresivo: Janiwa jiskhsnati, jicchuxa kunjamsa jakañani, qhiparuxa walixchiñanixaya (Z-L-7) ${ }^{78}$. (No podemos consentir decir: hoy vivamos como sea, con la esperanza posterior de alcanzar el bienestar). Las categorías de tiempo-espacio son inversas a la racionalidad dominante: el futuro no viene, sino queda atrás (qhipa pacha), se sabe que existe pero nadie sabe cómo será, es incierto; $\mathrm{y}$, el pasado queda delante (nayra pacha) y no atrás, es como estar presenciando los hechos y acontecimientos ("le constan a uno"). El bienestar no se alcanza sacrificando el presente, lo lógico es "estar bien" ahora y siempre. Está claro entonces que, en una realidad aparentemente compartida, no todos "vemos lo mismo" a pesar de ser seres biológicamente pertenecientes a una misma especie. Diríamos entonces que no son los ojos los que ven e interpretan la realidad, sino son nuestros esquemas de pensamiento o estructuras cognitivas que a través de los ojos ven e interpretan la realidad. Estos procesos cognitivos, así como los desarrollos del pensamiento, del lenguaje, etc., están directamente relacionados con los espacios físicos y culturales de cada individuo y sociedad.

76 Líder-Presidente Comunidad, Kelluyo.

77 Bermejo y Maquera, "Interpretación de la escuela rural andina", 12-13.

78 Líder-Presidente Comunidad-Distrito, Zepita. 


\section{CONCLUSIONES}

Desde los albores del siglo XX, la educación y la EIB se convierten, para los aimaras, en ideas fuerza, imaginarios colectivos, al intentar batallar en contra de las asimetrías de poder y los procesos seculares de homogeneización-asimilacionista. La presencia de la EIB en las escuelas rurales del ámbito aimara en Puno, Perú, se registra formalmente a partir de los años setenta del siglo pasado hasta la actualidad. Esta presencia de la EIB por más de cuarenta años, desde la racionalidad aimara, solo representa un valor simbólico, opera desde la educación como un programa racista, dirigido exclusivamente a los indígenas, restringiéndose en la escuela a lo lingüístico y cultural; se percibe como un montaje para encubrir la marginación y la exclusión, que son estructurales e históricas para los pueblos aimaras e indígenas. No ha fracasado la EIB sino la pretensión y el trasfondo diseñado mediáticamente como EIB. Ante esta realidad, los pueblos aimaras vienen planteando la autosegregación entendida como estrategia y racionalidad para redefinir la EIB, la educación en general y la subsistencia como nación indígena.

El valor simbólico de la EIB. Los indígenas aimaras, después de apropiarse de la escuela por más de un siglo, con la idea de recobrar el respeto y la dignidad humana, ante la práctica mortificante del desprecio a la vida y condición indígenas, hoy constatan que la educación recibida continúa encubriendo las diferencias objetivas de poder y las asimetrías sociales, poniendo incluso en crisis la representación que cada uno tiene de sí mismo. Según Bourdieu, citado por Tanja Rother $^{79}$, son los sistemas de educación los que contribuyen de manera importante a la continuidad de las desigualdades sociales. Ocurre sencillamente que las utopías y expectativas construidas colectivamente alrededor de las bondades que brindaría la escuela, no contrastan con los hechos que les toca vivir diariamente. Las leyes y políticas educativas generalmente adoptadas transcurrieron a nivel de simple enunciación, carentes de acciones pragmáticas y resultados concretos, configurando a la EIB como una educación compensatoria (inclusiva), de reconocimiento y valoración de la diversidad, entre indígenas pertenecientes a culturas distintas, respectivamente. Excepcionalmente, entre los acontecimientos a favor de la EIB en los últimos cuarenta años, se encuentran: a) la promulgación de la Reforma Educativa ${ }^{80}$ de 1972 (D. L. 19326), considerada como la más radical en la historia republicana del Perú, al reconocer desde el Estado que la educación se encontraba al servicio de una minoría privilegiada, coyuntura que permitió forjar las ideas medulares del pluralismo lingüístico y cultural del país, la emergencia del discurso y la teoría intercultural; y, la oficialización del quechua en 1975 ( D. L. n. ${ }^{\circ}$ 21156); b) el Proyecto Experimental de Educación Bilingüe Puno (1997, enero 1990), financiado por la GTZ alemana, posibilitó la

79 Tanja Rother, "Conflicto intercultural y educación en Chile: desafíos y problemas de la Educación Intercultural Bilingüe (EIB) para el pueblo Mapuche", Revista Austral de Ciencias Sociales, n. 9 (2005), 72. https://www.redalyc.org/pdf/459/45900907.pdf

80 Comisión de Reforma de la Educación. “Reforma de la educación peruana. Informe General” (Lima: MINEDU, 1970), 200. 
reflexión y desarrollo de una concepción intercultural en la educación a través de la implementación de los programas de educación bilingüe (transición y mantenimiento), para los seis niveles de la educación primaria, con producción de materiales y métodos de enseñanza-aprendizaje, fundamentalmente; $y, c)$ el Proyecto Educativo Regional Puno (PER-P) y el Proyecto Curricular Regional de Puno (PCR-P), construidos con participación y consenso de la sociedad civil bajo el enfoque de la educación intercultural bilingüe. No obstante su cantidad, todas estas iniciativas fracasaron y ninguna queda en pie.

La EIB como política racista y discriminatoria. Zúñiga ${ }^{81}$, refiriéndose a los programas EIB de las tres últimas décadas del siglo $X X$, señaló que estos se conciben casi con exclusividad para las poblaciones indígenas y son producto de la influencia de los académicos o de las corrientes de EBI vigentes en la región. Los aimaras, por regla general, conciben la EIB en las escuelas como un programa racista y discriminatorio, al estar exclusivamente dirigida a los indígenas y no a todos los peruanos; señalan que por su condición de ser pobres e indígenas han impuesto la EIB sistemáticamente desde las esferas del poder, solo para ellos. En este sentido, es permisible pensar que la diferencia cultural está subordinada a las desigualdades sociales y condiciones de vida precarias; y por tanto, se corre el riesgo de borrar la diferencia (cultura aimara) para revertir las desigualdades y la marginación. Los pueblos aimaras no desean estar condenados a la desigualdad por seguir siendo indígenas, ellos quieren ser indígenas, interculturales y vivir una vida con dignidad y armonía. Ser interculturales implica incorporar la racionalidad indígena con la misma prestancia que gozan las demás epistemologías, considerando que el desarrollo de nuestras formas de vida y conocimiento son milenarios y, por lo mismo, fuentes de aporte al mundo globalizado. He aquí algunas otras razones para optar por la autosegregación. Las prácticas racistas, según los indígenas aimaras, han borrado implícitamente la noción de interculturalidad; niegan haber participado en la concepción y toma de decisiones respecto a la EIB; por tanto la EIB no les pertenece, es una educación impuesta. Se usó y abusó de la interculturalidad para justificar la presencia indígena y como pretexto para encubrir la marginación y la exclusión; está claro que, mientras subsistan las asimetrías sociales y relaciones de poder, tanto en sociedad como en la escuela, la interculturalidad como tal no tiene cabida. Se pretendió asumir la interculturalidad desde los programas EIB como reproducción de actitudes y dinámicas sociales subordinadas a la racionalidad dominante. De este modo, la interculturalidad desde los programas EIB en el Perú se ha constituido en el modo más eficiente de legitimidad de la colonialidad del poder, el racismo.

EIB restringida a lo lingüístico y cultural. Los propósitos de la EIB establecidos en los Lineamientos de Política de Educación Bilingüe Intercultural y el Plan Nacional de Educación Intercultural Bilingüe al 2021, se dirigen a mejorar la calidad y equidad educativa, asumiendo la diversidad en las propuestas y expe-

81 Madeleine Zúñiga, La educación intercultural bilingüe. El caso peruano (Lima: FLAPE-Foro Educativo, 2008), 63. 
riencias educativas. Bajo este marco, desde la academia, las ONG y los decisores de políticas educativas desarrollaron algunos proyectos y acciones para el tratamiento de la diversidad cultural y lingüística, fundamentalmente, adaptando y alineando los procesos curriculares y didácticos a las teorías constructivistas y cognitivas, sin afrontar las brechas ocasionadas por la exclusión y la marginación de los pueblos indígenas. A través del tiempo, todas las experiencias de EIB desarrolladas en las escuelas rurales de la región de Puno, según diferentes fuentes de información, se abocaron básicamente al tratamiento lingüístico y cultural. En las comunidades aimaras, la EIB significa, o se entiende, únicamente como la enseñanza en aimara y castellano. Los programas EIB en las zonas aimaras de Puno han coadyuvado de manera progresiva, como se evidencia a través de los diferentes informantes y de los estudios realizados en Puno, que tanto padres, como escolares y docentes confieren al castellano mayor uso, estatus e importancia frente a la lengua aimara, abdicando en el trayecto el ideal del bilingüismo coordinado. Lo anterior demuestra que la EIB es, finalmente, un programa de castellanización, con grave amenaza de provocar una situación de desplazamiento lingüístico, irreversible para el aimara. Diacrónicamente, los desplazamientos lingüísticos generan, como resultado, no solo la extinción de la lengua, sino también de la cultura. Para evitar esta catástrofe, que es sistemática y gradual, los aimaras vienen ideando una posibilidad de respuesta que en este estudio hemos convenido en llamar como la autosegregación indígena, como estrategia de preservación y desarrollo natural de la lengua y cultura aimaras, respectivamente. Esta estrategia es concordante con lo sostenido por Rayner Hamel ${ }^{82}$ : “La preservación o incluso revitalización de la lengua y cultura indígena no se resolverá, en última instancia, en la escuela, aunque ésta puede coadyuvar a estos procesos. Dependerá de la capacidad de resistencia étnica que desarrolle el pueblo indígena"; entendida por nosotros también como autosegregación indígena. Los programas EIB no solo vienen generando un acentuado desplazamiento lingüístico, sino han consolidado durante décadas el poder y hegemonía del castellano: diglosia. La situación de diglosia como problema lingüístico en nuestro país, en lugar de suprimirse, se enquista y se ensancha, el castellano se ha convertido en el único idioma a través del cual se ejerce ciudadanía y se participa en la vida del país. ¿Dónde quedan el respeto y el diálogo intercultural? Históricamente, el poder colonial utilizó las lenguas indígenas con sentido aparentemente cultural y religioso; sin embargo, fueron estrategias para desestructurar la sociedad andina prehispánica y consolidar el poder colonial.

Los estudios, informes y balances presentados por diferentes fuentes de origen a las instancias oficiales del Estado, a las organizaciones financieras, en los espacios académicos, publicaciones y otros, dando cuenta de las ventajas y bondades de una EIB en Puno, se han desmoronado solos a través del tiempo

82 Rainer Enrique Hamel, "Determinantes sociolingüísticas de la educación indígena bilingüe", Signos: Anuario de Humanidades, 2 (1988), 369. https://www.researchgate.net/publication/264610119_Determinantes_sociolinguisticas_de_la_educacion_indigena_ bilingue 
(más de cuatro décadas), no contrastan con las condiciones de vida real en las que se encuentran actualmente los aimaras en Puno. Cueto y Secada ${ }^{83}$, después de haber implementado un trabajo de investigación en 28 escuelas rurales de Puno, interpelaron seriamente a los tomadores de decisiones por afirmar que, luego de treinta años de instaurado el programa EBI, esté completamente operativo, sentenciando: "Pueden mirar los resultados descritos aquí, concluir que el programa no funciona". Como remate, Zúñiga y Gálvez ${ }^{84}$ afirmaron en su momento que la implementación de la EBI ha sido bastante limitada y, lo más grave, es que no ha logrado mayor aceptación de los actores educativos; no ha influido en los programas curriculares para población rural, menos para escuelas urbanas y no tiene presencia en la sociedad nacional.

Las visiones e intenciones explicitadas oficialmente en los proyectos y programas de EIB colisionan frontalmente con los ideales y filosofía de la nación aimara. La escuela concebida desde los centros de poder y dirigida a los aimaras, vende la ilusión del bienestar en el futuro, lo que significa que esa pretensión es incierta, escapa a la lógica del pensamiento aimara. La escuela, vista como mecanismo que promueve la movilidad social o cambio de estatus a futuro, es incompatible, por cuanto desde el pensamiento aimara la escuela no puede ser una utopía de felicidad posterior, sino la garantía del bienestar permanente (hoy y siempre), del disfrute de la vida en armonía entre el hombre y la naturaleza.

El abordaje de la educación y la interculturalidad ostenta, por lo general, una tradición desde "fuera", procedente de los círculos académicos no indígenas. Hay necesidad de construir las teorías de la educación intercultural, articulando la reflexión indígena y no indígena o deja de ser intercultural. Los indígenas ${ }^{85}$ no fuimos convocados ni considerados para participar intelectualmente sobre la perspectiva de la EIB; incluso, los activistas o académicos aliados por la causa de la educación intercultural, parecen haber enviado el mismo mensaje: "esto se ha pensado para ustedes". Los indigenistas, según José C. Mariátegui -cita García $^{86}$ - , jamás serán capaces de retratar la "verdadera esencia" de la vida indígena. Por lo mismo, los indígenas no requerimos ser representados por otros, tenemos nuestras particulares concepciones y pensamientos que deben enriquecer y conjugarse con el pensamiento universal.

Por consiguiente; las anomalías en la concepción, en la definición de políticas y, sobre todo, en la implementación de la EIB para la población aimara en Puno, Perú, han generado como respuesta, la emergencia de una posibilidad de mantener y revitalizar la lengua y la cultura aimaras, estratégicamente, a través de sus propias organizaciones y sistemas de autogestión, denominada convencionalmente por nosotros como autosegregación indígena. La autosegregación, como proyecto ideológico, cultural y educativo, debe emprender la construcción

83 Cueto y Secada, "Eficacia escolar en escuelas bilingües", 19

84 Zúñiga y Gálvez, "Repensando la educación bilingüe”, 21.

85 Los autores del artículo nos autodefinimos como indígenas aimaras: nacimos y mantenemos vigente nuestro arraigo en territorio aimara, hablamos y escribimos en aimara.

86 María Elena García, Desafíos de la interculturalidad. Educación, desarrollo e identidades indígenas en el Perú (Lima: IEP, 2008 ), 303. 


\section{indígena en los aimaras de Puno, Perú}

de nuevas relaciones sociales basadas en el respeto y el crecimiento de la nación aimara como una fuerza dialogante y horizontal, insertada en el mundo global, que desde la escuela privilegie la formación del ser, haga frente a la injusticia cognitiva y la colonialidad del poder, básicamente.

\section{REFERENCIAS}

Abdallah-Pretceille, Martine. La educación intercultural. Barcelona: Idea Books, 2001.

Alanoca Arocutipa, Vicente, Ofelia Mamani Luque y Wido Condori Castillo. “El significado de la educación para la nación Aymara". Revista Historia de la Educación Latinoamericana 21, n. ${ }^{\text {. }}$ 32 (2019): 227-246.

Ansión, Juan. La escuela en la comunidad campesina. Lima: Proyecto Escuela, Ecología y Comunidad Campesina, 1988.

Beigel, Fernanda. "Mariátegui y las antinomias del indigenismo". Utopía y Praxis Latinoamericana 6, n. ${ }^{\circ} 13$ (2001): 36-57.

Bermejo Paredes, Saúl y Yanet A. Maquera Maquera. “Interpretación de la escuela rural andina en comunidades aimaras de Puno-Perú". Revista Electrónica Educare 23, n. ${ }^{\circ} 2$ (2019): 1-15.

Bermejo Paredes, Saúl y Yanet A. Maquera M. "Aimaras de Puno y la actitud minera: ¿para llegar a la vida hay que pasar por la muerte?". Revista de Investigaciones Altoandinas 18, n. ${ }^{\circ}$, (2016): 69-76.

Bermejo Paredes, Saúl. "Los mejores y últimos... ¿El PCR una realidad o un imaginario?". Los Andes, Puno, 11 de agosto, 2013. http://losandes.com.pe/oweb/Cultural/20130811/73891. html (29 de agosto, 2019).

Bermejo Paredes, Saúl. Hacia una educación intercultural. Crecer en un mundo plurinacional. Puno-Perú: Imp. San Valentín, 2010.

Bermejo Paredes, Saúl. Docencia y pedagogía de la educación bilingüe intercultural. Puno-Perú: ANAMEBI Perú-Región Puno, 2009.

Bermejo Paredes, Saúl. “La educación bilingüe en Puno. ¿Una historia del fracaso?”. Revista Investigaciones en Ciencias Sociales 2 (1994): 47-56.

Bermejo Paredes, Saúl. "Visión andina de la escuela oficial”. Tesis de maestría en Lingüística andina y Educación, Universidad Nacional del Altiplano, 1992.

Borboa-Trasviña, Marco A. "La interculturalidad: aspecto indispensable para unas adecuadas relaciones entre distintas culturas. El caso entre 'Yoris' y 'Yoremes' del centro ceremonial de San Jerónimo de Mochicahui, El Fuerte, Sinaloa, México". Revista: Ra Ximhai 2, n. 1 (2006): 45-71.

Centro Peruano de Estudios Sociales. La educación rural en el Perú: Opinan los maestros. Lima: CEPES, 1989.

Chirinos Almanza, Alfonso. "La reforma agraria peruana". Nueva Sociedad n. 21 (1975): 47-64.

Comisión de Reforma de la Educación. "Reforma de la educación peruana. Informe General". Lima: MINEDU, 1970.

Cueto, Santiago y Walter Secada. "Eficacia escolar en escuelas bilingües en Puno, Perú". REICE. Revista Iberoamericana sobre Calidad, Eficacia y Cambio en Educación 1, n. ${ }^{\circ} 1$ (2016). https:// revistas.uam.es/index.php/reice/article/view/5342. (05/09/2019).

Deustua Escarza, Alejandro O. "El problema pedagógico nacional". En La escuela rural: Variaciones sobre un tema, editado por Carmen Montero. Lima: FAO-PEEC, 1990.

Dirección Regional de Educación Puno/CARE Perú. Proyecto curricular regional de Puno. Sistematización de su proceso de construcción. Construcción social emergente de afirmación cultural y desarrollo. Puno-Perú: Editorial Altiplano EIRL, 2011.

Encinas Franco, José A. Un ensayo de escuela nueva en el Perú. Lima: Editorial Minerva, 1930.

García, María Elena. Desafíos de la interculturalidad. Educación, desarrollo e identidades indígenas en el Perú. Lima: IEP, 2008.

Garcilaso de la Vega, Inca. Comentarios reales de los incas. Buenos Aires: EMECÉ editores (1943). 
Godenzzi, Juan Carlos. "Introducción / Diversidad histórica y diálogo intercultural. Perspectiva latinoamericana". TINKUY, Sección de Estudios Hispánicos n. ${ }^{\circ} 1$ (2005): 7-14.

González Prada, Manuel. Páginas libres. Horas de lucha. Caracas: Biblioteca Ayacucho, 1976.

Guerrero, Gabriela. "Del dicho al hecho hay mucho trecho. Un análisis de la implementación de la política nacional de educación bilingüe intercultural en Puno". En Cambio y continuidad en la escuela peruana: una mirada institucional a la implementación de programas, procesos y proyectos educativos, editores Martín Benavides y Paul Neira. Lima: GRADE, 2010.

Hamel, Rainer Enrique. "Determinantes sociolingüísticas de la educación indígena bilingüe". Signos: Anuario de Humanidades (1988): 319-376.

Hornberger, Nancy H. Haku Yachaywasiman: la educación bilingüe y el futuro del quechua en Puno. Lima-Puno: Programa de Educación Bilingüe en Puno, 1989.

Instituto Nacional de Estadística. “Encuesta Nacional de Hogares, 2016-2017. Informe Técnico: Evolución de la pobreza monetaria 2007-2017". Lima: INEI, 2018.

Instituto Nacional de Estadística e Informática. "Perú: Perfil sociodemográfico. Informe Nacional. Censos Nacionales XII de población, VII de vivienda y III de comunidades indígenas". Lima: INEI, 2018.

López, Luis E. y Wolfgang Küper. “La educación intercultural bilingüe en América Latina: balance y perspectivas". Revista Iberoamericana de Educación n. 20 (1999): 17-85.

López, Luis E. "La educación bilingüe en Puno: hacia un ajuste de cuentas". En Educación bilingüe intercultural. Reflexiones y desafíos, editado por Madeleine Zúñiga, Inés Pozzi-Escot y Luis E. López. Lima: FOMCIENCIAS, 1991.

López, Luis E. e Ingrid Jung. Las lenguas en la educación bilingüe. El caso de Puno. Lima: GTZ, 1988.

Maguiña, Alberto. "La voz de Felipe Guamán Poma de Ayala". Autoeducación. Revista de educación popular n. 32 (1991): 41-52.

Maldonado López, Ezequiel. “'El sueño del pongo' y la traducción de una cultura”. Fuentes Humanísticas 28, n. ${ }^{\circ} 49$ (2014): 61-69.

Montoya, Rodrigo. Por una educación bilingüe en el Perú. Reflexiones sobre cultura y socialismo. Lima: CEPES/Mosca Azul Editores, 1990.

Ministerio de Educación del Perú, "Plan nacional de educación intercultural bilingüe al 2021". Lima: MINEDU, 2016. http://repositorio.minedu.gob.pe/handle/123456789/5105 (05 de setiembre, 2019).

Neira, Eloy y Patricia Ruiz B. “Enfrentados al patrón: una aproximación al estudio de las masculinidades en el medio rural peruano". En Estudios culturales. Discursos, poderes, pulsiones, editado por Santiago López, Gonzalo Portocarrero, Víctor Vich y Rocío Silva. Lima: Red para el Desarrollo de las Ciencia Sociales en el Perú, 2002.

Nueva Educación Bilingüe Multicultural en los Andes-EDUBIMA-CARE Perú. Una experiencia de construcción curricular participativa Azángaro-Puno. Lima: CARE-Perú, 2007.

Pease García, Franklin. "Las versiones del mito de inkarri". Revista de la Universidad Católica n. ${ }^{\circ} 2$ (1977): 25-41.

Pozzi-Escot, Inés. "Balance y perspectivas de la educación para poblaciones indígenas en el Perú". Allpanchis II, n. ${ }^{\text {ss } 35 / 63 ~(1990): ~ 393-434 . ~}$

Ramos Zambrano, Augusto. Aimaras rebeldes. Arequipa, Perú: Instituto de Estudios Pukara, 2007.

Rimanakuy-Cusco 1986. Conversatorio regional de comunidades campesinas del Sur-Este 1986. Cusco: Editorial Sur, 1986.

Rother, Tanja. "Conflicto intercultural y educación en Chile: desafíos y problemas de la Educación Intercultural Bilingüe (EIB) para el pueblo Mapuche", Revista Austral de Ciencias Sociales n. ${ }^{\circ}$ 9 (2005): 71-84.

Ruelas, David. "Los movimientos indígenas y la educación del siglo XX en el sur andino puneño, peruano". Revista Historia de la Educación Latinoamericana 21, n. ${ }^{\circ} 33$ (2019): 61-85.

Saavedra, Jaime y Pablo Suárez. Financiamiento de la educación pública en el Perú: el rol de las familias. Lima: GRADE, 2002. Documento de trabajo n.․ 38. http://bibliotecavirtual.clacso.org.ar/ Peru/grade/20100625014731/ddt38

Tamayo Herrera, José. Historia social e indigenismo en el altiplano. Lima: Ediciones Treintaitrés, 1982. Valiente Catter, Teresa. "Historia social, historia local y educación bilingüe". Allpanchis II, n. ${ }^{\text {s }}$ 29/30 
indígena en los aimaras de Puno, Perú

(1987): 401-430.

Von Gleich, Utta. La educación bilingüe en Puno. Puno-Lima: GTZ, 1994.

Walsh, Catherine. "Interculturalidad crítica y educación intercultural". En Construyendo Interculturalidad Crítica. La Paz, Bolivia: Instituto Internacional de Integración del Convenio Andrés Bello, 2010. https://aulaintercultural.org/2010/12/14/interculturalidad-critica-y-educacion-intercultural/ (11/09/2019).

Zúñiga, Madeleine. La educación intercultural bilingüe. El caso peruano. Lima: FLAPE-Foro Educativo, 2008.

Zúñiga, Madeleine y Modesto Gálvez. “Repensando la educación bilingüe intercultural en el Perú: bases para una propuesta de política". En Interculturalidad y política: desafíos y posibilidades, editado por Norma Fuller. Lima: Red para el Desarrollo de las Ciencias Sociales en Perú, PUCP-UP-IEP, 2002.

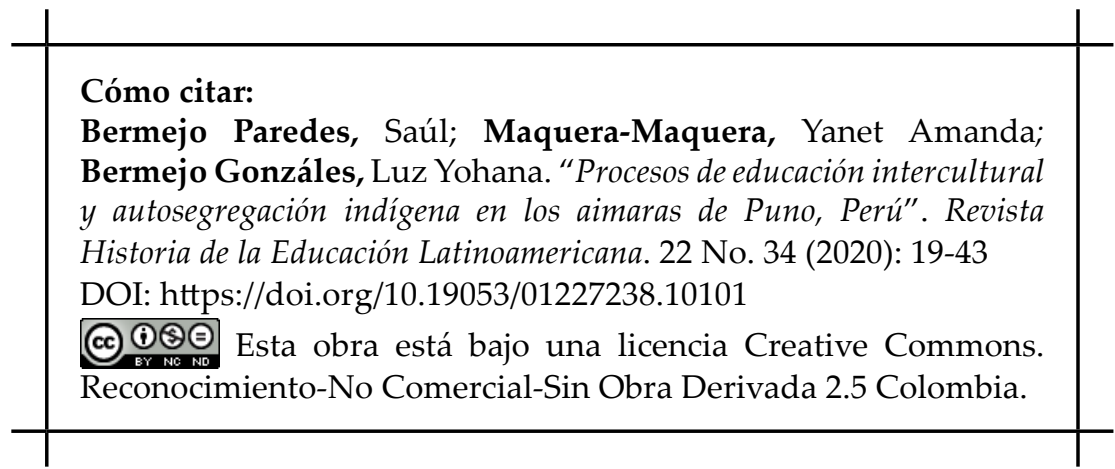


Saúl Bermejo Paredes, Yanet Amanda Maquera Maquera, Luz Yohana Bermejo Gonzáles 